ABDI: Jurnal Pengabdian dan Pemberdayaan Masyarakat ISSN: 2656-369X (Print), 2684-8570 (Online)

Volume 2 No. 1, Juni 2020

http://abdi.ppj.unp.ac.id/index.php/abdi

Email: abdi@ppj.unp.ac.id

DOI: https://doi.org/10.24036/abdi.v2il.42

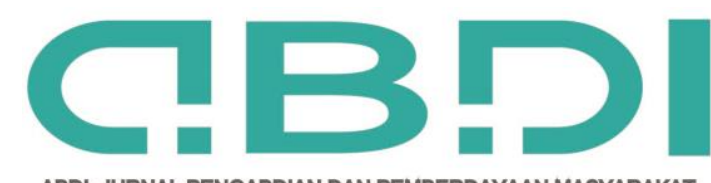

ABDI: JURNAL PENGABDIAN DAN PEMBERDAYAAN MASYARAKAT

\title{
Efektivitas Penyampaian Informasi Kesehatan untuk Meningkatkan Kepercayaan Diri Melalui Exercise Speaking Health
}

\author{
Evi Maria Lestari Silaban', Zul Amri ${ }^{2}$ \\ ${ }^{1}$ Jurusan Promosi Kesehatan Poltekkes Kemenkes RI Padang \\ Jurusan Gizi Poltekkes Kemenkes RI Padang \\ E-mail: eviechielaban@yahoo.co.id, zulamri6464@ gmail.com
}

\begin{abstract}
Abstrak
Isu yang diangkat adalah belum efektifnya keterampilan komunikasi mahasiswa sarjana terapan promosi kesehatan dalam penyampaian informasi kesehatan dari sisi kepercayaan diri, sasaran dan penggunaan bahasa di Jurusan Promosi Kesehatan Kemenkes Padang. Berdasarkan isu tersebut penulis mengangkat judul "Efektivitas Penyampaian Informasi Kesehatan untuk meningkatan kepercayaan diri melalui Exercise Speaking Health”. Kegiatan ini terdiri dari 1) Melakukan koordinasi dengan pimpinan Perguruan Tinggi; 2) Melakukan Penyusunan Bahan Sosialisasi; 3) Persiapan Sosialisasi Exercise; 4) Kegiatan Sosialisasi Exercise; 5) Pelaksanaan Exercise Speaking Health; 6) Melakukan Assesment; 7) Melakukan Evaluasi Pelaksanaan Edukasi. Kegiatan Exercise Speaking Health merupakan Pemberian latihan untuk mengefektifkan penyampaian informasi kesehatan guna meningkatkan kepercayaan diri melalui exercise speaking health di kelas bagi mahasiswa Sarjana Terapan Promosi Kesehatan yang telah terlaksana dengan baik. Evaluasi pelaksanaan edukasi ini dilaksanakan melalui pre-post test dan praktik berkomunikasi sebnayak 3 kali. Hasil evaluasi menunjukkan terdapat perbedaan dari setiap tahap praktik berkomunikasi yang dilakukan oleh mahasiswa, perubahan cara berkomunikasi dari yang belum efektif menjadi efektif dimulai dari praktik yang pertama sampai praktik ketiga. Cara berkomunikasi yang baik dapat menjadi sarana penyampaian pesan kepada masyarakat, ketika mahasiswa melakukan tugasnya sebagai seorang promotor kesehatan.
\end{abstract}

Kata kunci: Komunikasi Kesehatan, Kepercayaan Diri, Exercise Speaking Health

\section{Abstract}

The issue raised was the ineffectiveness of communication skills applied by undergraduate students in health promotion in the delivery of health information in terms of confidence, goals and use of language in the Ministry of Health Promotion of the Ministry of Health. Based on these issues the authors raised the title "Effectiveness of Health Information Submission to increase self-confidence through Exercise Speaking Health ". This activity consists of 1) Coordinating with the leaders of Higher Education; 2) Arranging the Socialization Material; 3) Preparation for Exercise Socialization; 4) Exercise Socialization Activities; 5) Implementation of Exercise Speaking Health; 6) Conduct an Assessment; 7) Conduct Educational Evaluation. Exercise Speaking Health activity is the provision of exercises to streamline the delivery of health information in order to increase confidence through health speaking exercises in class for Applied Health Promotion Bachelor students who have done well. Evaluation of the implementation of this education is carried out through pre-post tests and the practice of communicating as much as 3 times. Evaluation results show that there are differences in each stage of communication practice undertaken by students, changes in the way of communication from ineffective to effective starting from the first practice to the third practice. A good way of communicating can be a means of delivering messages to the public, when a student performs his duties as a health promoter

Keywords: Health Communication, Self Confidence, Exercise Speaking Health

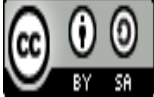

Received: 1 Februari 2020 


\section{Pendahuluan}

Isu merupakan suatu hal yang terjadi baik di dalam maupun di luar organisasi yang apabila tidak ditangani secara baik akan memberikan efek negatif terhadap organisasi bahkan dapat berlanjut pada tahap krisis. Pendidikan Program Diploma IV Promkes merupakan pendidikan Sarjana Terapan Promkes yang menghasilkan lulusan Promosi Kesehatan yang memiliki peran sebagai implementator Promosi Kesehatan, pemberdayaan Masyarakat, pengembang media promosi kesehatan, fasilitator tim promosi kesehatan, advocator promosi kesehatan, dan asisten peneliti promosi kesehatan. dari informasi diperoleh bahwa masih ada mahasiswa tingkat III jurusan Promosi Kesehatan yang belum mampu berkomunikasi secara efektif dalam penyampaian informasi kesehatan pada saat adanya kegiatan praktek di lapangan. Sehingga penyampaian pesan belum terealisasi kepada masyarakat, hal ini dapat menyebabkan salah satu ketidakberhasilan ketercapaian profil lulusan (Notoatmodjo, 2010).

Di dalam lingkup promosi kesehatan, seorang promotor kesehatan yaitu mahasiswa lulusan Sarjana Terapan Promosi Kesehatan yang nantinya akan mengimplementasikan dirinya di tengahtengah masyarakat harus mampu berkomunikasi secara efektif dalam penyampaian edukasi kesehatan, sehingga informasi kesehatan dapat sampai kepada sasaran yang dituju serta sasaran dalam edukasi kesehatan mampu dan mau melakukan pesan dari promotor. Bila promotor tidak mampu berkomunikasi secara efektif, maka perubahan perilaku yang nantinya diharapkan sebagai hasil dari edukasi kesehatan tidak dapat terlaksana dengan baik ("Pentingnya Komunikasi dalam Pelayanan Kesehatan Primer," 2015).

Fokus pengabdian masyarakat yang akan dilakukan agar mahasiswa mampu untuk melakukan komunikasi kesehatan dengan menggunakan strategi komunikasi melalui proses perencanaan dan pengembangan media pesan untuk menginformasikan dan mempengaruhi keputusan individu dan/atau komunitas dalam perubahan perilaku kesehatan yang terlait konsep komunikasi kesehatan, analisis masalah kesehatan dan perilaku, strategi komunikasi, pengembangan pesan dan media komunikasi, perencanaan media promosi kesehatan dan tehnologi komunikais online (Notoatmodjo, 2010).

\section{Metode Pelaksanaan}

Pelaksanaan kegiatan merupakan rangkaian kegiatan yang dilaksanakan berdasarkan kerangka pemecahan masalah yang disusun. Isu yang diangkat, "Belum efektifnya Keterampilan Komunikasi Mahasiswa Sarjana Terapan Promosi Kesehatan dalam penyampaian Informasi Kesehatan dari sisi kepercayaan diri, sasaran dan penggunaan bahasa di Jurusan Promosi Kesehatan Poltekkes Kemenkes Padang" merupakan hasil observasi dan diskusi peserta selama di lingkungan kerja. Berikut ini merupakan kerangka kerja yang disusun: (a) Melakukan Koordinasi terkait pelaksanaan rancangan kegiatan pengabdian kepada masyarakat. (b) Melakukan penyusunan Bahan Exercise Speaking Health, (c) Persiapan Sosialisasi Exercise, (d) Kegiatan Sosialisasi Exercise, (e) Pelaksanaan Exercise Speaking Health, (f) Melakukan Assessment, (g) Melakukan Evaluasi Pelaksanaan Edukasi. (Sunarni, Judistiani, Hinduan, Sukandar, \& Madjid, 2017).

Sasaran kegiatan pengabdian kepada masyarakat ini adalah mahasiswa semester V Prodi Sarjana Terapan Promosi Kesehatan Poltekkes Kemenkes Padang, dengan metode:

a. Melakukan kegiatan Exercise Speaking Health kepada mahasiswa tingkat III Prodi Sarjana Terapan Promosi Kesehatan Poltekkes Kemenkes Padang

b. Memberikan latihan-latihan dalam berkomunikasi efektif kepada mahasiswa tingkat III Prodi Sarjana Terapan Promosi Kesehatan Poltekkes Kemenkes Padang melalui metode exercise speaking health.

c. Melakukan evaluasi hasil kegiatan menggunakan daftar tilik untuk melihat perubahan berkomunikasi pada mahasiswa tingkat III Prodi Sarjana Terapan Promosi Kesehatan Poltekkes Kemenkes Padang. (Wibowo \& Suryani, 2013). 


\section{Hasil dan Pembahasan}

Hasil dan Pembahasan kegiatan dapat dideskripsikan pada tablel berikut:

\section{Tabel 1. Rincian Kegiatan 1}

\begin{tabular}{lc}
\hline Kegiatan 1 & Melakukan Koordinasi terkait pelaksanaan rancangan kegiatan \\
pengabdian kepada masyarakat
\end{tabular}

\begin{tabular}{l|l}
\hline Output & $\begin{array}{l}\text { Rancangan Kegiatan Pengabdian Masyarakat telah dilaporkan } \\
\text { dan disetujui oleh pimpinan }\end{array}$ \\
\hline Manfaat & $\begin{array}{l}\text { Manfaat dari Kegiatan ini: } \\
\text { 1. Rencana Kegiatan Pengabdian Masyarakat telah dilaporkan } \\
\text { kepada pimpinan dan mendapatkan dukungan. }\end{array}$
\end{tabular}

2. Melakukan konsultasi tentang kegiatan Exercise Speaking Health.

Tabel 2. Rincian Kegiatan 2

\begin{tabular}{ll}
\hline Kegiatan 2 & \multicolumn{1}{c}{ Penyusunan Bahan Sosialisasi } \\
\hline Deskripsi Kegiatan & Penulis menyusun bahan sosialisasi dengan sistematis, \\
dimulai dari mencari dan mengumpulkan daftar pustaka \\
hingga mencetak bahan exercise. Dalam penyusunan ini, \\
penulis selalu berkonsultasi dengan mentor agar kegiatan \\
Exercise Speaking Health ini dapat dihabituasikan \\
kedepannya. Keberhasilan kegiatan ini nanti dapat menjadi \\
pertimbangan untuk dimasukkan ke dalam kegiatan \\
ekstrakurikuler.
\end{tabular}

Kontribusi terhadap visi dan misi organisasi
1. Tercapainya visi Politeknik kesehatan Unggulan

2. Mengembangkan tata kelola organisasi yang baik (good governance) dalam memberikan pelayanan yang prima 
Manfaat
Manfaat dari penyusunan ini:

1. Mengumpulkan daftar pustaka untuk bahan sosialisasi

2. Mendapatkan persetujuan pimpinan untuk bahan exercise

3. Bahan Sosialisasi Exercise telah disusun dan dicetak.
Tabel 3. Rincian Kegiatan 3 Kegiatan 3

Deskripsi Kegiatan

\section{Persiapan Sosialisasi Exercise}

Penulis berkoordinasi dengan Koordinator Akademik dan sekretaris jurusan dalam menentukan waktu pelaksanaan kegiatan Exercise Speaking Health, dimana kegiatan direncanakan akan dilakukan pada angkatan 2017 (Tingkat III). Dilanjutkan dengan membuat daftar tilik untuk penilaian dan daftar hadir. Saat berkoordinasi dengan Koordinator Akademik, penulis meminta saran tentang jadwal kegiatan yang disesuaikan dengan kalender akademik. Diharapkan pembelajaran yang diberikan dapat meningkatkan kemampuan berkomunikasi mahasiswa, khususnya dalam teknik penyampaian pesan

\begin{tabular}{ll}
\hline $\begin{array}{l}\text { Kontribusi terhadap } \\
\text { visi dan } \\
\text { organisasi }\end{array}$ & $\begin{array}{l}\text { 1. Tercapainya visi Politeknik kesehatan Unggulan } \\
\text { 2. Mengembangkan tata kelola organisasi yang baik (good } \\
\text { governance) dalam memberikan pelayanan yang prima }\end{array}$ \\
\hline Output & $\begin{array}{l}\text { 3. Menyelenggarakan Pendidikan Vokasi dan Profesi yang } \\
\text { inovatif dengan berlandaskan Ketaqwaan kepada Tuhan Yang } \\
\text { Maha Esa. }\end{array}$ \\
\hline Manfaat & Jadwal Exercise \& daftar tilik telah disusun \\
\hline & $\begin{array}{l}\text { Manfaat dari persiapan ini: } \\
\text { 1. Mendapatkan masukkan dari pimpinan. } \\
\text { 2. Menghasilkan daftar tilik sebagai panduan penilaian dalam } \\
\text { kegiatan exercise speaking health. }\end{array}$ \\
\hline
\end{tabular}

Tabel 4. Rincian Kegiatan 4

\begin{tabular}{ll}
\hline Kegiatan 4 & \multicolumn{1}{c}{ Kegiatan Sosialisasi Exercise } \\
\hline Deskripsi Kegiatan & Kegiatan sosialisasi dilaksanakan pada hari Senin, penulis \\
mengumpulkan mahasiswa tingkat III di ruang kuliah, sebelum \\
melaksanakan sosialisasi penulis meminta peserta untuk \\
mengisi daftar hadir, dan dilanjutkan dengan pemaparan bahan \\
sosialisasi, penulis memaparkan bahan sosialisasi yang berjudul \\
Komunikasi Efektif materi pemaparan dibuat dalam bentuk \\
leaflet. Topik sosialisasi disesuaikan dengan judul kegiatan \\
aktualisasi yaitu efektifitas penyampaian informasi kesehatan \\
untuk meningkatkan kepercayaan diri melalui exercise speaking \\
health, mahasiswa tertarik dan antusias untuk mengikuti \\
kegiatan ini dikarenakan kegiatan ini sebenarnya sudah sering \\
dilakukan di dalam kehidupan sehari-hari terutama dalam \\
aktivitas pembelajaran yaitu berkomunikasi, tetapi mahasiswa \\
belum optimal dan belum mengetahui bagaimana metode \\
berkomunikasi yang baik agar pesan yang disampaikan dapat di \\
pahami dan dilakukan oleh masyarakat, hal ini juga dilihat dari
\end{tabular}




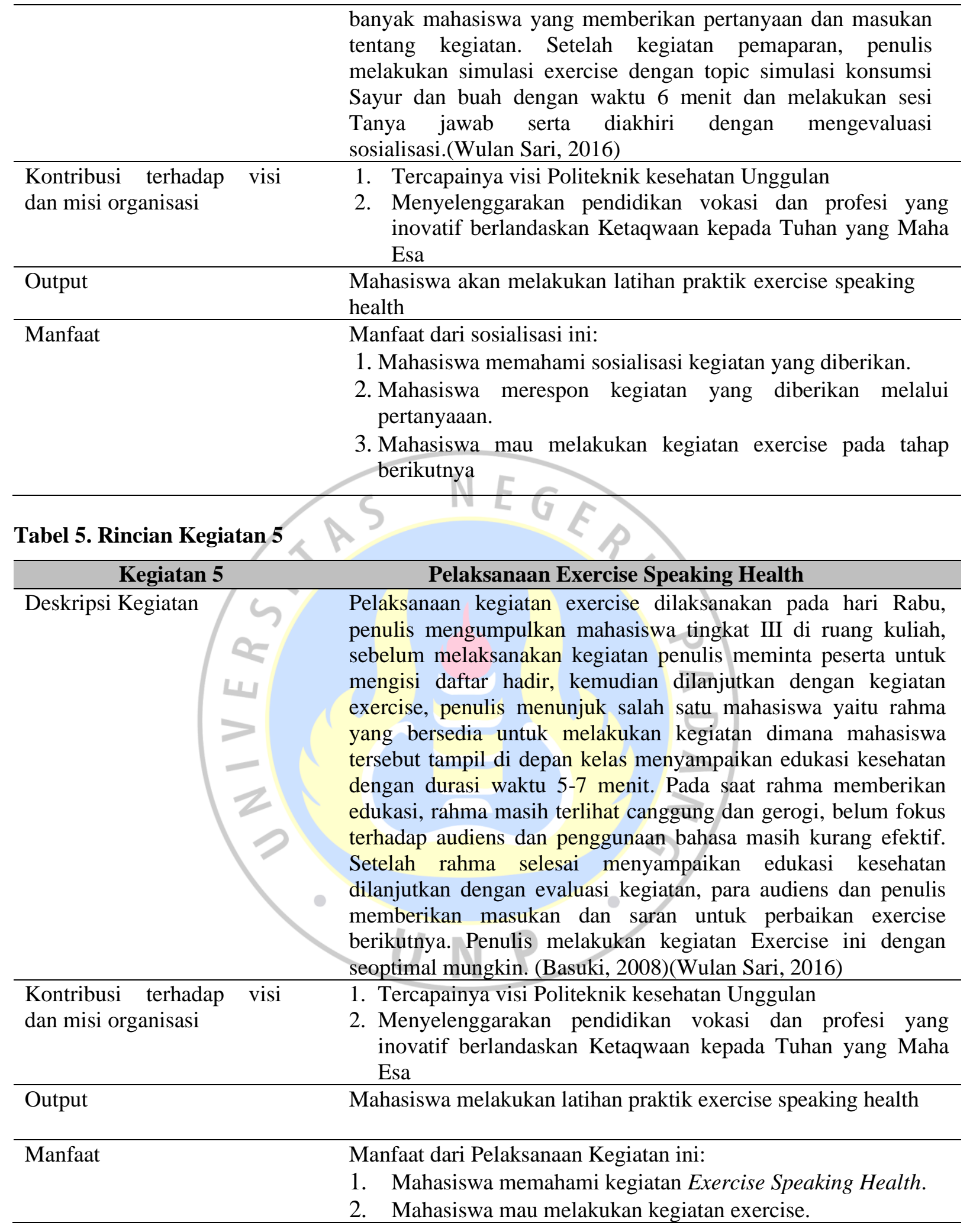


Tabel 6. Rincian Kegiatan 6

\section{Kegiatan 6}

Deskripsi Kegiatan

\section{Melakukan Assesment}

Penulis memberikan tugas kepada mahasiswa untuk melakukan exercise speaking health di kelas sebanyak $3 \mathrm{x}$ dengan topic yang sama. Kegiatan ini dimaksudkan agar pada setiap tahap exercise terjadi perubahan komunikasi yang lebih baik. Untuk mengetahui perubahan cara berkomunikasi dari tahap pertama sampai ketiga digunakan daftar tilik. Pada tahap pertama exercise : Cara berkomunikasi peserta masih banyak yang perlu diperbaiki, terkhususnya dari segi menggunakan dan mempertahankan eye contac, bahasa tubuh serta pengunaan humor yang berlebihan.

Pada tahap kedua: Skala yang diperoleh dalam teknik berkomunikasi sudah mendapatkan rata-rata nilai 1 pada setiap skala, ini menandakan adanya kemajuan yang baik pada saat menyampaikan informasi.

Pada tahap ketiga komunikasi sudah mulai bagus dan optimal, dilihat dari perubahan penilaian, dari 11 kriteria penilaian, 7 kriteria sudah mendapatkan skala maksimal.(Basuki, 2008)(Wahyuni, Yanis, \& Erly, 2013)

\begin{tabular}{lll}
\hline $\begin{array}{l}\text { Kontribusi terhadap visi dan } \\
\text { misi organisasi }\end{array}$ & $\begin{array}{l}\text { 1. Tercapainya visi Politeknik kesehatan Unggulan } \\
\text { 2. Menyelenggarakan pendidikan vokasi dan profesi yang } \\
\text { inovatif berlandaskan Ketaqwaan kepada Tuhan yang Maha } \\
\text { Esa }\end{array}$ \\
\hline Output & $\begin{array}{l}\text { Didapatkan perubahan berkomunikasi kearah yang lebih baik } \\
\text { mulai praktik 1 sampai praktik ke 3, (lampiran Daftar Tilik) }\end{array}$ \\
\hline Manfaat & $\begin{array}{l}\text { Manfaat dari Assesment ini: } \\
\text { 1. Mahasiswa memahami dan dapat melakukan kegiatan } \\
\text { Exercise. }\end{array}$
\end{tabular}

2. Mahasiswa mampu berkomunikasi khususnya tentang kesehatan lebih baik dari sebelumnya.

\section{Tabel 7. Rincian Kegiatan 7}

\begin{tabular}{ll}
\hline \multicolumn{1}{c}{ Kegiatan 7} & \multicolumn{1}{c}{ Melakukan Evaluasi Pelaksanaan Edukasi } \\
\hline Deskripsi Kegiatan & $\begin{array}{l}\text { Kegiatan ini dilakukan dengan membuat laporan hasil evaluasi } \\
\text { dan menyajikan data serta melaporkan hasil laporan kepada } \\
\text { pimpinan. Pelaporan dalam bentuk hasil evaluasi dilengkapi } \\
\text { dengan foto dan video }\end{array}$
\end{tabular}

Kontribusi terhadap visi dan misi organisasi
1. Tercapainya visi Politeknik kesehatan Unggulan

2. Menyelenggarakan pendidikan vokasi dan profesi yang inovatif berlandaskan Ketaqwaan kepada Tuhan yang Maha Esa

Output

Laporan hasil evaluasi

Manfaat
Manfaat dari evaluasi ini:

1. Dilaporkannya kegiatan Pengabdian Masyarakat kepada pimpinan.

2. Kegiatan dapat direkomendasikan untuk masuk dalam kegiatan Ekstrakurikuler 


\section{Kesimpulan}

Kegiatan Pengabdian kepada Masyarakat "Efektivitas Penyampaian Informasi Kesehatan untuk meningkatan kepercayaan diri melalui Exercise Speaking Health" dilaksanakan pada mahasiswa tingkat III (tiga) Program Studi Sarjana Terapan Promosi Kesehatan". Kegiatan ini terdiri dari 7 (tujuh) kegiatan. Kegiatan Exercise speaking health ini bertujuan untuk Memberikan pemahaman kepada mahasiswa tentang komunikasi efektif, Mengembangkan potensi mahasiswa dalam berkomunikasi efektif serta Memberikan latihan-latihan dalam berkomunikasi efektif di Jurusan Promosi Kesehatan Poltekkes Kemenkes Padang menggunakan metode Exercise Speaking Health. Tujuh kegiatan yang penulis lakukan antara lain koordinasi dengan unsur pimpinan, penyusunan Bahan Exercise Speaking Health, Persiapan Sosialisasi Exercise, Kegiatan Sosialisasi Exercise, Pelaksanaan Exercise Speaking Health, Melakukan Assesment, dan Melakukan Evaluasi Pelaksanaan Edukasi. Kegiatan ini diserap dengan baik oleh mahasiswa. Hal ini terlihat adanya perubahan teknik berkomunikasi yang terjadi mulai dari praktik 1 sampai praktik ke 3. Selama kegiatan, mahasiswa sangat antusias terlihat dengan aktif bertanya dan memberikan masukan.

\section{Daftar Pustaka}

Basuki, E. (2008). Komunikasi antar Petugas Kesehatan. Majalah Kedokteran Indonesia, 58(9), 340345.

Kementrian Kesehatan RI. (2011). Promosi Kesehatan di Daerah Bermasalah Kesehatan. Kementrian Kesehatan RI. https://doi.org/kementerian kesehatan ri pusat promosi kesehatan

Kholid, A. (2018). Promosi Kesehatan dengan Pendekatan Teori Perilaku, Media, dan Aplikasinya. Jakarta: Raja Grafindo Persada.

Notoatmodjo, S. (2010). Komunikasi Kesehatan: Promosi Kesehatan Teori dan Aplikasi. Jakarta: Raja Grafindo Persada.

Notoatmodjo, S. (2012). Promosi Kesehatan dan Perilaku Kesehatan. Journal of Chemical Information and Modeling, 2(1), 11-19. https://doi.org/10.1017/CBO9781107415324.004

Sunarni, N., Judistiani, T. D., Hinduan, Z. R., Sukandar, H., \& Madjid, T. H. (2017). Hubungan Keterampilan Komunikasi Interpersonal dan Konseling oleh Mahasiswa Kebidanan dengan Kepuasan Klien di Bidan Praktik Mandiri. Jurnal Pendidikan dan Pelayanan Kebidanan Indonesia, 3(2), 38-46. https://doi.org/10.24198/ijemc.v3i2.38

Wahyuni, T., Yanis, A., \& Erly, E. (2013). Hubungan Komunikasi Dokter-Pasien Terhadap Kepuasan Pasien Berobat di Poliklinik RSUP DR. M. Djamil Padang. Jurnal Kesehatan Andalas, 2(3), 175-177.

Wibowo, S., \& Suryani, D. (2013). Pengaruh Promosi Kesehatan Metode Audio Visual dan Metode Buku Saku Terhadap Peningkatan Pengetahuan Penggunaan Monosodium Glutamat (MSG) Pada Ibu Rumah Tangga. Jurnal Kesehatan Masyarakat (Journal of Public Health), 7(2), 1040. https://doi.org/10.12928/kesmas.v7i2.1040.

Wulan Sari, A. (2016). Pentingnya Ketrampilan Mendengar dalam Menciptakan Komunikasi yang Efektif. EduTech: Jurnal Ilmu Pendidikan dan Ilmu Sosial, 2(1),1-10. 
Evi Mria Lestari Silaban, Zul Amri Efektivitas Penyampaian Informasi Kesehatan untuk Meningkatkan Kepercayaan Diri Melalui Exercise Speaking Health

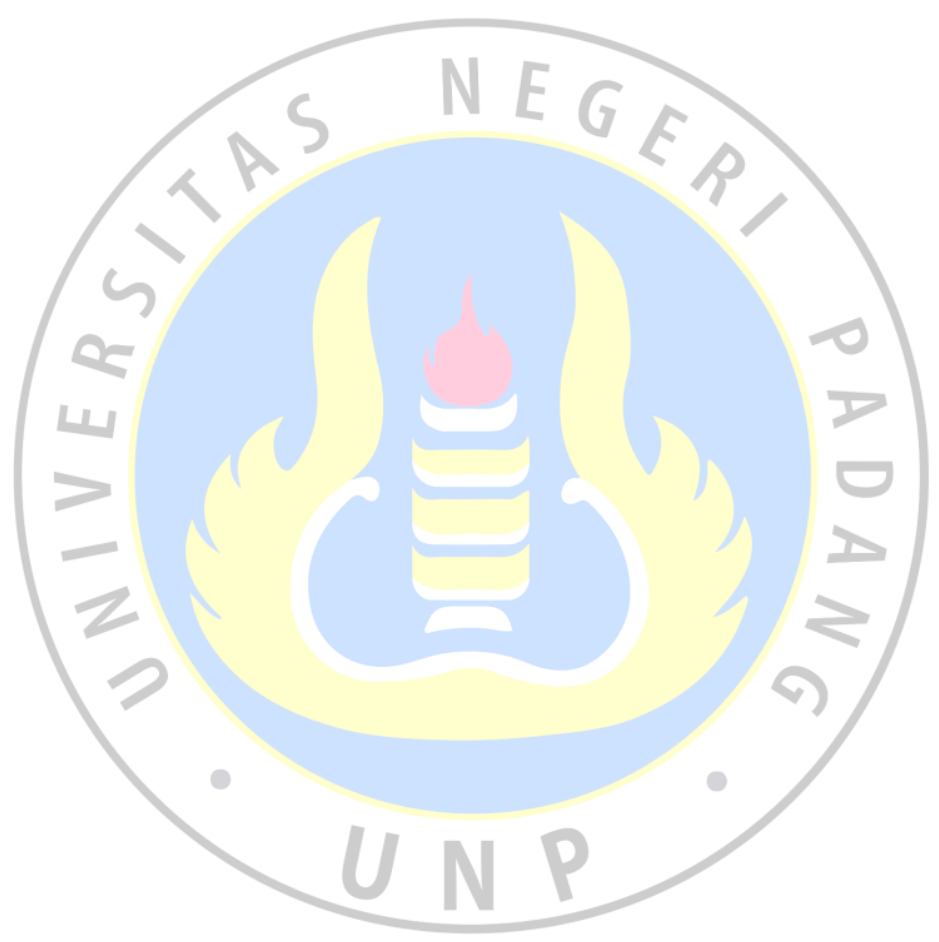

